INVESTIGACIÓN/RESEARCH

Recibido: 17/07/ 2014 --- Aceptado: 04/09/2014 ---Publicado: 15/09/2014

\title{
IMPORTANCIA DE LA EDUCACIÓN PUBLICITARIA
}

María Teresa Pellicer Jordá1: Universidad de Murcia. España. maite.pellicer@um.es

\section{RESUMEN}

El presente trabajo analiza la publicidad y la necesidad de educar a la población en esta materia. Nuestro objetivo con este artículo es demostrar la necesidad de educar a la ciudadanía, especialmente a los niños, para que aprendan a leer publicidad y, así, minimizar sus efectos negativos en la sociedad. Para ello, vamos a analizar la situación publicitaria actual, prestando especial atención al público infantil, con el fin de conocer y entender con mayor detalle la necesidad de una educación publicitaria. También conoceremos la importancia de la escuela en esta labor que planteamos. Todo esto nos permitirá concluir que - al igual que ocurre en el resto de ámbitos de la vida- la educación es la única opción para solucionar todos los problemas que se derivan del gran volumen de anuncios al que estamos expuestos cada día, para hacer ciudadanos realmente libres respecto al consumo y de ofrecer a la sociedad una auténtica capacidad autónoma respecto a la publicidad, como herramienta del sector capitalista.

PALABRAS CLAVE:

Publicidad - Educación - Sociedad - Comunicación - Ética - Valores - Moral -Niños - Colegio

\section{IMPORTANCE OF THE ADVERTISING}

\begin{abstract}
The present work analyzes the advertising and the need to educate the population in this matter. Our aim with this article is to demonstrate the need to educate the citizenship, specially the children, in order that they learn to read advertising and,

María Teresa Pellicer Jordá ${ }^{1}$ La autora es profesora en la Facultad de Comunicación y Documentación de la Universidad de Murcia. Es autora de dos libros, titulados ‘Ética y estrategias publicitarias' y 'La publicidad como industria cultural', así como de varios artículos en revistas especializadas en Comunicación.

maite.pellicer@um.es
\end{abstract}


this way, to minimize its negative effects in the society. For it, in this article we are going to analyze the current advertising situation, paying particular attention to the infantile public, in order to know and to understand with greater detail the need of an advertising education. Also we will know the importance of the school in this labor that we raise. All that will allow us to conclude that - as it happens in the rest of areas of the life - the education is the only option to solve all the problems that stem from the great volume of advertisements to which we are exposed every day, to make really free citizens with regard to the consumption and of offering to the society an authentic autonomous capacity with regard to the advertising, as tool of the capitalist sector.

\section{KEYWORDS}

Advertising - Education-Society - Communication - Ethics - Values - Mulberry tree Children-School.

\section{INTRODUCCIÓN}

El protagonismo de la publicidad en la sociedad en la que vivimos es innegable. Si contáramos los anuncios que vemos cada día, de forma voluntaria e involuntaria, nos sorprenderíamos del volumen al que estamos expuestos. Como explica Noguera, "desde pequeños asumimos que la publicidad forma parte del escenario cotidiano que rodea y acompaña nuestra existencia. Nos sigue allá donde vamos, está presente aunque no la miremos, ni escuchemos sus llamadas (2006:46)". Esa exposición masiva es la que hace obligatoria preparar al consumidor para leer la publicidad, para saber lo que se puede esperar de ella y esa preparación debe realizarse desde el sistema educativo, con el fin de garantizar la correcta interpretación de la misma y reducir sus aspectos negativos en la sociedad. Por ello, en este artículo vamos a plantear con detalle la cuestión y ofrecer argumentos que apoyen esta labor educativa, muy necesaria, a nuestro juicio, en la sociedad actual.

\section{OBJETIVOS Y METODOLOGÍA}

En este artículo vamos a demostrar la necesidad de ofrecer una educación a la ciudadanía en materia de publicidad. Para ello, vamos a ofrecer argumentos y datos que pongan de manifiesto la importancia de la cuestión, a través de la revisión bibliográfica de numerosos autores expertos en las materias de educación y publicidad.

\section{DISCUSIÓN}

Lo primero que debemos hacer es definir Publicidad, ya que es imprescindible acotar el concepto para saber de lo que estamos hablando. Según la Ley General de Publicidad, la Publicidad es: 
Es toda forma de comunicación realizada por persona física o jurídica, pública o privada en el ejercicio de una actividad comercial, artesanal, industrial o profesional con el fin de promover la contratación de forma directa o indirecta de bienes inmuebles, servicios, derechos y obligaciones (Normacivil, 2010).

La Publicidad, por tanto, se encarga de fomentar las ventas, convirtiéndose en uno de los elementos fundamentales de la sociedad capitalista y sin la cual sería muy difícil su funcionamiento. Esa constituiría su función económica - y a la vez función principal- pero lo cierto es que la sociedad actual y, de acuerdo a su intensa presencia en la misma, ha dado lugar a otra serie de funciones, que no debemos olvidar, ya que como afirma Noguera "a nadie se le escapa que la publicidad ejerce otras funciones derivadas de su actividad principal, que es la venta (2006:46)". Según Furones, estas funciones serían las siguientes (1980:9):

Función informativa: informa al consumidor sobre los productos y servicios disponibles.

Función financiadora: $\sin$ duda, la publicidad contribuye a financiar los medios de comunicación.

Función sustitutiva: la publicidad opera sustituyendo la presentación de un objeto real, tal como es, por un elaboradísimo mensaje con el que, en ocasiones, vende un producto que es todo lo contrario de lo que dice que es.

Función estereotipada: por su difusión masiva, la publicidad tiende a igualar gustos, criterios, ideales. Resultan muy interesantes los estudios que investigan las relaciones entre publicidad y cambio social en grupos concretos. Sorprendería saber cuánto han influido en hábitos de consumo, en relaciones afectivas, en modos de vida.

Función desproblematizadora: la publicidad tiende a presentar un mundo divertido, lúdico, fascinante, en el que la mayoría de los productos se consumen en momentos de ocio, nunca durante el trabajo. Esta imagen del lado bello de la vida, explotada por el mundo publicitario, pretende desdramatizar la vida cotidiana, suavizar el otro lado: el de la crisis, el paro, la inflación, la violencia, el dolor, la muerte, la desigualdad social.

Función conservadora: la publicidad siempre enseña lo ya visto, habla de lo ya hablado. Detrás de su aparente continua innovación, lo que en realidad procura es hacer parecer como nuevo lo ya aceptado.

Estas funciones hacen de la publicidad un fenómeno muy importante y, por tanto, digno de ser estudiado y enseñado a todos los ciudadanos. Como dice Eguizábal, "pensar que lo esencial publicitario consiste en vender géneros es tan ingenuo como pensar que lo esencial de la moda es cubrir nuestra desnudez o protegernos contra el frío (2007:7)". De ahí que, si analizamos la evolución de la publicidad, podemos comprobar que a lo largo de las últimas décadas se ha ido produciendo un paulatino deslizamiento de la publicidad como entidad económica a la publicidad como fenómeno cultural. Eso sí, esto no ocurre en todo el mundo, sino solamente en los países ricos, ya que sólo en el caso de que estén cubiertas las necesidades básicas, se podrá intentar crear otras necesidades- tal y como hace la publicidad. 
La publicidad, por tanto, tiene una presencia muy importante en nuestras vidas, pero ¿la conocemos lo suficiente? Como plantea Eguizábal, "probablemente no existe nada en la cultura actual tan presente y tan desconocido a un tiempo, para el ciudadano medio, como la publicidad (2009:9)". El autor da una posible explicación a esto, diciendo que:

Al igual que otras formas de poder, la publicidad tiende a no manifestarse, a ocultar sus armas, a disimularse. El público, que contempla todos y cada uno de los días de su vida un número imponente de mensajes publicitarios, lo desconoce todo o casi todo de sus estructuras, las organizaciones y las ideas que hay detrás de ellos (2009:9).

Esta reflexión del autor es muy interesante porque es curioso como un fenómeno tan conocido por todos, por su intensa presencia en nuestras vidas, puede ser a la vez tan desconocido para todos.

Desconocemos, de este modo, su influencia en nuestras vidas, a pesar de que "la realidad demuestra que los efectos a largo plazo de la publicidad en nuestras vidas son reales y efectivos (Noguera y Cristofol:46)". Como afirma Costa, "la publicidad puede considerarse como parte determinante de los actos de los individuos, ligados al consumo y a su ritual. Y a través de ello, es un generador vertiginoso de los modelos que configuran nuestro imaginario social (1992:11)". Añade que autor que "está claro que la publicidad es una industria y, como tal, debe velar por su negocio. Pero es una industria cultural, que no fabrica productos materiales que el público compra, consume y destruye, sino que fabrica mensajes, información y modelos de conducta (Costa, 1992:14)". Esta postura es compartida por muchos autores y organismos. La publicidad modela comportamientos, como vemos, pero también transmite valores, en unos casos nuevos y en otros los que ya están presentes en la sociedad (Ferrer Rosello, 1992:19).

Una vez demostrada la importancia y gran influencia de la publicidad en la sociedad actual, debemos preguntarnos cuál es la posición del receptor en todo este proceso. Según Caridad Hernández.

El receptor de la comunicación publicitaria no es pasivo, sino que pone en juego una serie de mecanismos cognitivos con ayuda de los cuales selecciona, capta e interpreta la información dirigida a él, poniéndose en el lugar del emisor, y tomando parte en el proceso de interacción que culminará con un tipo de respuesta concreta (Ferrer Rosello, 1992:75).

En este sentido, Gerardo Pastor explica que "reclamos publicitarios, aun los más cautivadores, transmiten imágenes y mensajes cuyos contenidos, falseados o no, completos o sesgados, son procesados por personas receptoras muy capaces de desenmascarar un embuste $y$ de rechazarlos, por audiencias quizá reacias a aceptarlos (Bonete, 1999:173)". En cualquier caso, ya sea con base racional o emocional, el receptor tiene un papel activo en la comunicación publicitaria.

Como dice Lakoff:

El proceso comunicativo ya no es visto desde los presupuestos reduccionistas de la medición de efectos, sino desde la óptica más comprensiva de una construcción simbólica de la realidad. Y este cambio de paradigma va 
asociado a una concepción más activa del público, que ya no es considerado como un simple objeto que reacciona ante ciertos estímulos, sino como un sujeto activo más de la comunicación (1995:28).

Según estos enfoques, el receptor activo tiene la capacidad para descifrar el mensaje, pero la cuestión es en este caso si el receptor tiene las claves adecuadas para descifrar estos mensajes de forma correcta, sobre todo teniendo en cuenta que la publicidad recurre cada vez más a lo emocional para vender sus productos y servicios, lo que provoca que la libertad de elección del receptor se vuelva ciertamente más débil. Los consumidores adultos hemos visto nacer y desarrollarse a la publicidad, pero nadie nos ha enseñado a descifrarla. Nosotros la hemos leído como hemos considerado, sin indicaciones previas sobre cómo hacerlo. Sería difícil aprender a leer un texto de forma correcta si antes no hemos aprendido las vocales y las consonantes. Lo mismo ocurre con la publicidad, que se ha manifestado inmerso en nuestros medios de comunicación como un componente más, cuando es un componente con matices diferentes que conviene conocer. Si esto es necesario de cara a los adultos, más necesario se hace en el caso de los niños, ya que, como explica Soria, "la verdad y, sobre todo, la persuasión, se hacen más problemáticas cuando sus destinatarios tienen la ingenuidad y la inmadurez de los pocos años (Bonete, 1999:158)". Los niños se convierten así en indefensos consumidores "incapaces de protegerse a sí mismos contra los engaños y las tentaciones a que los someten los vendedores o los predicadores indoctrinantes (Bonete, 1999:166)", como explica Gerardo Pastor. Muchas empresas se aprovechan de esta situación y centran áun más sus esfuerzos en los pequeños, llegando a patrocinar, incluso, campañas de educación nutricional, su material escolar o entrando en la escuela a través de máquinas expendedoras, situaciones ya habituales en Estados Unidos, aunque en España no han llegado todavía a implantarse con tal intensidad (Shor, 2006:28-29).

El interés en los niños es claro. Como dice Clyde Miller, es "una labor que lleva tiempo, pero que vale la pena si se piensa en los beneficios que pueden obtenerse al condicionar a millones de niños que algún día serán adultos dispuestos a comprar determinados productos (Bonete, 1999:158)". A eso se suma que los niños constituyen un público amplio en número, que condicionan las compras de sus padres, como afirma José Luis León, y a los que les resulta más difícil distinguir entre ficción y realidad, ya que no es hasta los 8 o 9 años, los niños no empiezan a desarrollar su capacidad de razonar (Bonete, 1999:158). Además, es a partir de esa edad cuando el niño empieza a compararse con los demás (Tierno y Giménez,2004:96). Todo eso permite seducirles con mayor facilidad.

Lo cierto es que, cuando analizamos los datos de exposición de los niños a la publicidad, la importancia de la cuestión aumenta. Según un informe del Consejo de Europa, un niño de diez años de nuestro entorno geopolítico ha visto más de doscientos mil anuncios, puesto que ese niño pasa de 25 a 30 horas semanales ante el aula sin muros, lo que equivale a las horas que emplea en los centros de enseñanza (Madrid, 2006:21). De este informe se desprenden otros datos, como que más del 90 por ciento de los niños de tres años, o sea una edad todavía preescolar, comienzan a pedir a sus padres los juguetes anunciados en televisión. Bernabé Tierno afirma que: 
Los niños de entre 9 y 12 años pasan, al menos, cuatro horas diarias ante el televisor y los fines de semana se superan con creces las cinco o seis horas, podemos afirmar que cualquier niños ve al año 1.500 horas - o más- de televisión, mientras que en el colegio pasa alrededor de 1.000 horas. Si partimos de la base de que una de las vías de aprendizaje es la observación, nos encontramos con que la televisión constituye un punto de referencia esencial para nuestros hijos (2004:139-140).

Si tenemos en cuenta que la publicidad se inserta en los medios de comunicación, especialmente en la televisión - por sus características tales como la rapidez (Ramonet, 2002:193) o el color se hace el medio más idóneo como soporte publicitario-, podemos hacernos una idea de la exposición publicitaria tan intensa a la que se ven sometidos los niños. Medios y publicidad aúnan sus esfuerzos con el objetivo principal de vender, objetivo al que le siguen otros, derivados de la propia actividad, ya que:

El fenómeno comunicacional es, sin duda, la nota más trascendental y significativa que caracteriza la sociedad del mundo contemporáneo. (...) Como indica Moreno, la imagen y el sonido tecnificados penetran en nuestras vidas y condicionan, no sólo lo que comemos, bebemos o hacemos, sino incluso lo que deseamos y soñamos, pues los medios han venido a suplir una serie de satisfacciones sustitutivas de las experiencias directas y reales (Aguaded, 2001:14).

Ahora cabe preguntarnos cuáles son las consecuencias de la intensa actividad publicitaria. Según los estudiosos de la materia, los niños con tan sólo tres años consideran que las marcas, con los valores que transmite, expresan sus características personales. Esto es especialmente importante si tenemos en cuenta que "el egocentrismo es una característica de los niños entre 3 y los 6 años. Este rasgo de su personalidad les hace pensar que su punto de vista es único, que no existen otras alternativas (Tierno y Jiménez, 2004:47)". Esos valores que desde pequeños adquirimos son los que "reflejan la personalidad de los individuos y son la expresión del tono moral, cultural, intelectual, afectivo y social marcado por la familia, la escuela, las instituciones y la sociedad en que vivimos (Tierno y Jiménez, 2004:137)". Como explica Madrid Cánovas, "frente al comercio tradicional, en el que el objeto identificaba a los productores, gracias a la publicidad los objetos acaban identificando a quienes los consumen (2006:199)". Además, la publicidad trabaja con metáforas y como dice Lakoff:

Las metáforas pueden crear realidades, especialmente realidades sociales. Una metáfora puede así convertirse en guía para la acción futura. Estas acciones desde luego se ajustarán a la metáfora. Esto reforzará la capacidad de la metáfora de hacer coherente la experiencia. En este sentido, las metáforas pueden ser profecías que se cumplen (1995:198).

Y esas profecías que intenta transmitir la publicidad, el que un producto identifica a quien lo consume, es lo que da lugar a que aparezcan problemas de depresión, baja autoestima y ansiedad en los pequeños (Shor, 2006:223), que no siempre pueden tener el juguete o producto deseado, y en los mayores, que han sido educados en esa 
cultura consumista y con esos valores muy marcados. Ilustrativo es el fragmento que hemos extraído del libro 'Un mundo feliz', de Huxley, en el que se dice (1985:51):

- Cada hombre, cada mujer, cada niño tenía la obligación de consumir un tanto al año. Para favorecer la industria. El único resultado...

- Vale más desechar que tener que remendar. Cuanto más remiendo, más pobre me siento.

- Eso acabará mal el mejor día- dijo Fanny tristemente.

- Escrupulosas objeciones en gran escala: era cosa de no consumir, el retorno a la naturaleza.

Tras plantear la cuestión, debemos abordar la posible solución. En este sentido, hay que señalar que los adultos de hoy en día han aprendido a leer la publicidad de forma gradual, ya que ellos comenzaron a verla cuando todavía era un fenómeno económico, con argumentos racionales, y fueron viendo su evolución a una publicidad cultural, basada en los valores y emociones. Pero los niños han conocido sólo esa publicidad emocional, la más peligrosa si no se sabe interpretarla. Por eso, consideramos que la educación es la solución definitiva a este problema, para evitar que los niños sufran las consecuencias negativas de la publicidad, ya que ni las leyes vigentes ni los códigos deontológicos existentes en la actualidad, son capaces de eliminar estos efectos. Esto es así porque "es evidente que si queremos cosechar unos determinados valores, debemos sembrarlos y cosecharlos en la práctica. Si pretendemos que nuestros alumnos sean participativos, críticos, cooperativos, solidarios, el ejercicio educativo tiene que ser participativo, crítico, cooperativo y solidario (2004:107)", como dice Antonio Pérez.

Además, como explica Antonio Pérez, "la educación está adquiriendo una importancia cada vez mayor en todo el mundo, pues se la considera el elemento clave para abatir la pobreza, aumentar la productividad y formar a personas autónoma y ciudadanos honestos y responsables (2004:150)" y enseñar a los niños a leer publicidad, teniendo en cuenta la influencia que ésta tiene en la vida y personalidad de los ciudadanos, los hará realmente autónomos y libres $\mathrm{y}$, como dice Tuts, eso "depende de todos los agentes educativos, y desde el aula jugamos con ventaja (2006:13)".

La publicidad y la escuela tienen en común el hecho de formar parte de nuestras vidas, lo que convierte a "la escuela en un instrumento imprescindible en nuestra sociedad industrializada y constituye una herramienta esencial si queremos estar preparados para adaptarnos a los numerosos cambios a los que estamos expuestos (Tierno y Jiménez, 2004:62)". Tuts añade en este sentido que:

Educar no sólo desde la escuela, sino desde todos los ámbitos de la formación, es formar personas para su integración en la sociedad y su participación ciudadana solidaria y responsable. Eso cuestiona, entre otros, el papel tradicionalmente reproductor de la escuela: enseñamos los valores del pasado. El presente y el futuro se quedan para los contextos extraescolares... y surge la fractura con la realidad y el microcosmos escolar. Con la llegada de las vías rápidas de comunicación, Internet, las retransmisiones por satélite, la información nos provoca, nos reta (2006:11).

Y uno de esos retos es la educación publicitaria. Como explica Tierno. 
Una sociedad en la que sólo se dé valor e importancia al dinero, a la riqueza, a la fama, a lo material y no se tengan en cuenta otro tipo de valores, como el respeto, la buena convivencia, la justicia, la solidaridad, etc, irá deshumanizándose gradualmente hasta destruirse a sí misma. Por eso, es tan importante que los padres y educadores entendamos que los valores que inculquemos a nuestros hijos son determinantes para su futuro y para el futuro de generaciones venideras (2004:138-139).

De este modo, si dejamos que la publicidad sea libremente leída, sin formación previa, seguiremos contribuyendo a esa sociedad, ya existente, en la que lo material es lo único importante. De hecho, tal y como transmite la publicidad actual, lo material es lo que da la felicidad, el bienestar y la alegría de los ciudadanos.

Como dice Aguaded:

Preparar a los ciudadanos, y en especial a los jóvenes, para hacer frente a los desafíos de la comunicación en esta nueva sociedad de la información, se hace más necesario en la medida en que la escuela toma conciencia del trascendente papel que los medios van adquiriendo en la transmisión del saber social. (...) En este contexto, y como indica Area, nadie duda de la poderosa influencia sobre los ciudadanos y de su importante potencial pedagógico $\mathrm{y}$, por ello, de la necesidad de integrarlos en los procesos de enseñanza (2001:19).

El autor establece una serie de razones por las que considera importante educar a los ciudadanos en los medios de comunicación (2001:22):

1. Las altas dosis de consumo de comunicación

2. La influencia ideológica de la comunicación en la sociedad contemporánea.

3. La construcción de la información/realidad por los medios

4. La progresiva influencia de los medios en el desarrollo democrático de los pueblos.

5. La creciente importancia del código audiovisual en todas las esferas.

6. La acuciante necesidad de la escuela de actualizar contenidos y preparar para el futuro.

7. La transformación de la comunicación en un bien de consumo, en manos de empresas mercantiles.

\section{CONCLUSIONES}

Como decíamos, los medios de comunicación son los principales soportes publicitarios, por lo que educar a los ciudadanos - y en especial a los niños- en los medios de comunicación, supone educarlos en el ámbito publicitario, ya que la publicidad constituye uno de los contenidos principales de los medios, contenidos sin los cuales no podrían sobrevivir los medios. Aguamed aboga por conseguir "un análisis crítico de los medios (2001:33)" y a eso nosotros añadimos un análisis crítico de 
la publicidad, que permita a los ciudadanos conocer bien sus claves, procedimientos y técnicas y, así, ofrecerles una verdadera libertad de elección. Como dice Ballesta:

La escuela debe ser consciente del efecto mediático en la sociedad del conocimiento, que pasa necesariamente por abordar el papel que tienen los medios masivos en la sociedad actual y plantear, al mismo tiempo, una postura reflexiva y argumentada que nos lleve a clarificar actuaciones sobre las significaciones que le damos a las diferentes propuestas recibidas desde los media (2009:180).

El autor añade que:

El gran error consiste en suponer que quien va a utilizar los medios ya tiene formación suficiente para hacerlo, lo que no suele ser cierto en la mayoría de los casos. Se necesitaría tener un conocimiento previo o un requerimiento adquirido por el análisis desde la experiencia personal, cultural y grupal, capaz de servir de referente a lo que nos llega desde los medios (Ballesta, 2009:181).

Por todo esto, consideramos, como dice Ballesta, que "el alumnado debería recibir, durante su paso por la escolarización obligatoria, una formación para la comprensión de los medios, de sus mensajes, en las actividades y materias de conocimiento que desarrolla (2009:184)".

La publicidad, por tanto, ha pasado de ser un fenómeno económico a un fenómeno cultural su presencia en nuestras vidas es cada vez más abundante e intensa. A pesar de todo eso y de que es clara y demostrada su influencia y poder en nuestras vidastransmite valores y modelos de comportamiento-, es una gran desconocida para los ciudadanos, especialmente para los niños, que desconocen sus claves y forma de leerla e interpretarla. Cuando uno lee un periódico o ve un informativo, entiende que es realidad lo que se cuenta. Cuando uno va al cine, entiende que es ficción -en la mayor parte de los casos- lo que se cuenta. Pero cuando uno ve un anuncio, ¿pensamos que es realidad o ficción? Pues bien, eso es lo que hay que enseñar a los ciudadanos: saber distinguir una de otra, saber qué es lo que se espera de la publicidad y qué es lo que realmente nos ofrece. Y la única manera de enseñar todo eso y de hacer ciudadanos más libres, autónomos y responsables, es a través de la enseñanza. Sólo a través de ella conseguiremos este objetivo, ya que ella es la que ofrece las herramientas e instrumentos para conocer e Interpretar el mundo y, por ende, es la que nos debería explicar cómo interpretar la publicidad.

\section{REFERENCIAS}

\section{Capítulo de un libro o entrada de un libro de consulta: Libros completos:}

Aguaded Gómez, J.I. (2001). La educación en medios de comunicación. Murcia. Editorial KR. 2001. Pág. 14.

Aznar, H.(1999). Comunicación Responsable. Barcelona. Ariel Comunicación. Pág. 164165 
Ballesta Pagán, J. (2009). Educar para los medios en una sociedad multicultural. Barcelona. Editorial Da Vinci.

Bonete, E. (2006). Ética de la comunicación audiovisual. Madrid. Tecnos. Pág.173.

Costa, J. (1992). Reinventar la publicidad. Reflexiones desde las Ciencias Sociales. Madrid. Fundesco. Pág. 11.

Eguizábal, R. (2009). Industrias de la conciencia: una historia social de la publicidad en España (1975-2009). Barcelona. Península. Pág. 9

Eguizábal, R. (2007). Teoría de la publicidad. Madrid. Cátedra. Pág. 7

Ferrer Roselló, C. (1992). Genios y monstruos de la publicidad. Madrid. Dossat. Pág. 19.

Furones, M. A. (1980). El mundo de la publicidad. Barcelona. Salvat. Pág. 9

Huxley, A. (1985). Un mundo feliz. México. Editores mexicanos unidos. Pág. 51

Lakoff, G. y Jonson, M. (1995). Metáforas de la vida cotidiana. Madrid. Cátedra.

Madrid Cánovas, S. (2006). Semiótica del discurso publicitario. Murcia. Universidad de Murcia. Pág. 21.

Noguera, A. y Cristófol, C. (2006). Falsedad y comunicación. Valencia: Universidad de Málaga. Pág. 46.

Pérez Esclarín, A. (2004). Educar para humanizar. Madrid. Narcea

Ramonet, I. (2002). La tiranía de la comunicación. Barcelona. Editorial Debate. Pág. 193

Shor, J. (2006). Nacidos para comprar. Los nuevos consumidores infantiles Barcelona. Paidós Ibérica. Pág. 28-29.

Tierno, B.y Giménez, M. (2004). La educación y la escuela de 8 a 10 años. Madrid. Santillana Familia.

Publicaciones periódicas:

Artículos en papel y electrónicos:

Normacivil (2010). Ley General de la Publicidad

(http://civil.udg.es/normacivil/estatal/contract/Lgp.htm) (10-5-2010)

\section{María Teresa Pellicer Jordá}

Es doctora por la Facultad de Comunicación de la Universidad de Murcia, donde trabaja como profesora de las asignaturas Técnicas de investigación publicitarias, Responsabilidad y Autorregulación Publicitarias y Deontología de la Comunicación Audiovisual. Es licenciada en Periodismo y en Publicidad y Relaciones Públicas. Ha escrito dos libros, titulados 'La publicidad como industria cultural' y 'Ética y estrategias publicitarias', así como numerosos artículos en revistas especializadas. Además, posee una amplia experiencia en el campo de la comunicación, ya que durante varios años estuvo trabajando en reconocidos medios de comunicación de la Región de Murcia. 